\title{
The Comparative Effect of Using Competitive and Cooperative Learning on the Oral Proficiency of Iranian Introvert and Extrovert EFL Learners
}

\author{
Hamid Marashi \\ Islamic Azad University at Central Tehran, Iran \\ Padideh Dibah \\ Islamic Azad University at Central Tehran, Iran
}

\begin{abstract}
This study investigated the effect of cooperative and competitive learning on the oral proficiency of introvert and extrovert Iranian EFL learners. For this purpose, 120 learners were selected from a total number of 172 studying at a private language school in Tehran through a TSE. They also answered the Eysenck Personality Inventory which in turn categorized them into two subgroups within each learning modality setting consisting of introverts and extroverts. All in all, there were four subgroups: 30 introverts and 30 extroverts undergoing the cooperative learning treatment, and 30 introverts and 30 extroverts experiencing the competitive learning treatment. Another TSE was administered as the posttest and a two-way ANOVA was run on the mean scores of the four groups in the posttest to test the four hypotheses of this study. The results showed that while learners generally benefitted more from the competitive setting compared to the cooperative one, the extrovert group was better off receiving cooperative instruction. Furthermore, introverts outperformed extroverts in the competitive group; yet there was no difference between the two personality subgroups in the cooperative setting. Overall, introverts in both the cooperative and competitive settings benefitted more than extroverts.
\end{abstract}

Index Terms-oral proficiency, extroverts, introverts, cooperative learning, competitive learning

\section{INTRODUCTION}

When asked about language and what it is, a non-linguist would most probably provide the very common-place response that language is synonymous with speaking. To many an individual, speaking is the most important language activity which perhaps remains to be the most problematic skill as well. This may be so since this ability which "as such is usually viewed as the most complex and difficult skill to master" (Tarone, 2005, p. 485) is a skill which "cannot be ignored in the EFL classroom since people often judge a person's language knowledge/competence and proficiency level based on how well his/her speaking performance on the target language is" (Chuang, 2009, p. 72). At the same time, it appears that speaking is indeed the most demanding of the four skills both for students to master and, naturally, for teachers to teach (Hedge, 2008; Lennon, 1990; Lazaraton, 1996; Warschauer, 1996).

To this end, Riggenbach (1991) argues that a learner's ability to speak expresses the success of the process of learning and teaching in most classroom contexts. This is perhaps simply because speaking is an integrally indispensible part of everyday life (Griffiths, 2008; Levelt, Roelofs, \& Meyer, 2000; Luchini, 2007; Shumin, 1997; Tuan \& Neomy, 2007). Moreover, "The observable nature of speaking as a productive skill motivates learners to further indulge in the process of SLA" (Rashtchi \& Keyvanfar, 2007, p. 135).

Needless to say, there are varying reasons for EFL learners to wish to master their oral pro ficiency such as "to keep up rapport in relationships, influence people, and win or lose negotiations" (Hedge, 2008, p. 261) and, indubitably, variation in the different forms and tasks of oral activities in the EFL classroom is required to maximize the learning of this highly complex cognitive skill which involves several different mechanisms (Ellis \& Yuan, 2003; Jianing, 2007). Accordingly, various different teaching/learning modalities and also personality variables have been and still are looked into as part of the ongoing quest to enhance EFL learners' speaking in the classroom.

Extroverts/Introverts

In line with the aforementioned quest, there has been a growing awareness and sensitivity in the last few decades towards the importance of teachers' knowing more about the personality styles of learners which can be defined as "the relatively enduring style of thinking, feeling, and acting that characterizes an individual" (Costa, McCrae, \& Kay as cited in Navidnia, 2009, pp. 80-81). This awareness is of course partially - if not mainly - due to the impact clinical psychology has borne on school psychology in modern times thus emphasizing the individual personality dimensions of learners (Na, Lin-Yao, \& Ji-Wei, 2008) in the continuous endeavor to keep all learners satisfied (Senel, 2006).

A personality dimension that has attracted huge attention in L2 research is extroversion/introversion (Dornyei, 2005). Eysenck, Eysenck, and Barrett (1985) describe the extroverted type as those having characteristics such as sociability, 
liveliness, and excitability while the introverted type as those with a tendency towards taciturnity and reclusiveness. Furthermore, Richards and Schmidt (2002, p. 195) define an extrovert as one whose "conscious interaction is more often directed towards other people and events than towards the person themselves" while an introvert as one "who tends to avoid social contact with others and is often preoccupied with his/her feelings, th oughts, and experience".

Extroversion and introversion can also be viewed from a physiological angle. Chamorro-Premuzic (2007) holds that extroversion is "the psychological consequence of physiological differences in the reticulo-cortical system which determines levels of motivation, emotion, and conditioning according to either inhibitions or excitation of the cerebral cortex" (p. 23). He further writes that, "These consistent patterns of arousibility would also determine the extent to which an individual is extroverted or introverted and the primary facts of extroversion are warmth, gregariousness, assertiveness, activity, excite ment-seeking, and positive emotions" (p. 23).

Introverts do not take action unless they are ready and they tolerantly pay attention to a specific subject for a long stretch of time without getting distracted (John \& Srivastava, 1999). Sharp (2003) draws the line between extroversion and introversion by saying that extroverts mostly gather their data out of experience, whereas introverts engender their perspectives from inner, personal factors. That is why introverts endeavor to replace noisy crowds with quiet environments (Chamorro-Premuzic, 2007). Burruss and Lisa Kaenzig (1999) describe extensively the differences between the two categories of personality types by stating that while introverts are usually taciturn, uninterested in participating in social gatherings, more apt for non-group work, and tend to think and concentrate more before talking, extroverts enjoy and need social gatherings, engage in friendships with many people, tend to come up with quick responses, and try to avoid solitude.

It is not clear, however, whether extroversion or introversion "helps or hinders the process of second language acquisition" (Brown, 2000, p. 155) albeit there is a commonly-held belief among language teachers pointing to the issue that extroverts outperform the introverts in L2 learning, especially in terms of being superior in communicative abilities (Spada \& Tomita, 2010). As Dornyei (2005) puts it, "Both extroversion and introversion may have positive features, depending on the particular task in question" (p. 27). He points out that, "Extroverts are found to be more fluent in both L1 and L2 and particularly in formal situations or in environments characterized by interpersonal stress" (p. 26) and continues that introverts, however, are more interested in activities such as reading, writing, and drawing than activities which require the $m$ to act in an outgoing way.

\section{Competitive Learning}

Apart from the different personality variables that impact L2 learning, one cannot ignore the role of the modality of learning. An established dichotomy in this regard of course is competitive and cooperative learning (Walters, 2000). Competitive learning (win-lose orientation) is used for the purpose of evaluating the position of people in various tasks (Johnson, Maruyama, Johnson, \& Nelson, 1981). Deutsch, Coleman, and Marcus (2006) hold that the desired constructive form of competitiveness happens when the winner tries to lend a hand to the loser. Contrarily, in destructive competitiveness, the winner takes it all. They further state that, "Competition induces and is induced by use of the tactics of coercion, threat, or deception" (p. 31)

Furthermore, Johnson, Johnson, and Stanne (2000) hold that competitive learning prioritizes competition among the me mbers of the same group and not necessarily between different groups.

\section{Cooper ati ve Learning}

Contrary to competitive learning, cooperative learning exists when students work together to accomplish shared learning goals (Johnson et al., 2000). While in contrast with the social Darwinist paradigm of competition being at the heart of the survival of the fittest, cooperative learning favors a win-win orientation and gained momentum following the critique of social scientists such as Hartup, Ladd, Lewis, and Rosenblum (all cited in Johnson \& Johnson, 2009) on competitiveness.

A cooperative classroom, Johnson and Johnson (2008) state, should not be teacher-centered and "Ideally, teachers are trained to take their existing lessons and restructure them to be cooperative as cooperative learning is the instructional use of small groups so that students work together to maximize their own and each other's learning" (p. 26).

Accordingly, Deutsch et al. (2006) name the essential elements in cooperative learning as: positive interdependence, individual accountability and personal responsibility, promotive interaction, appropriate use of social skills, and group processing. The students' success depends on the achievement of all group members and the social problems involved in the process of learning are tackled (Johnson et al., 2000). In addition, Norman (2005, p. 3) writes that, "Cooperative learning is important for creating inclusive classroom environments that meet the needs of all students because it takes the heterogeneity into account, encouraging peer support and connection".

Past research has provided sufficient evidence that personality factors are heavily implicated in the learning processes in general and in SLA in particular (Dornyei, 2005). Therefore, the prime motive behind this research was to see whether the oral proficiency of introvert and extrovert EFL learners could be influenced by the use of competitive or cooperative language learning. Accordingly, these two instructions, namely competitive and cooperative and their effects on oral proficiency of introverts and extroverts, are compared to see which one is more effective on EFL learners' oral proficiency.

In order to fulfill the purpose of this study, the following null hypotheses were formulated: 
$H_{01}$ : There is no significant difference between the effect of competitive and cooperative learning on introvert EFL learners' oral proficiency.

$H_{02}$ : There is no significant difference between the effect of competitive and cooperative learning on extrovert EFL learners' oral proficiency.

$H_{03}$ : Competitive learning does not have a significantly different effect on the oral proficiency of introvert and extrovert EFL learners.

$H_{04}$ : Cooperative learning does not have a significantly different effect on the oral proficiency of introvert and extrovert EFL learners.

\section{METHOD}

\section{A. Participants}

To fulfill the objectives of this study, 120 female intermediate EFL learners with the age range of 17-30 studying in Tehran's Safir Language School participated in this study. These participants were selected through an oral langu age test, i.e. the Test of Spoken English (TSE, produced by the Educational Testing Services) from 172 learners in the same language school. The very first session of the class, the students received the Eysenck Personality Inventory (EPI) which identifies the degree of a person's introversion or extroversion.

This research was conducted in two terms. In the first term, nine classes with a total of 60 learners (30 introvert and 30 extrovert learners) were held where all of the learners underwent a cooperative learning procedure while in the next term, another nine classes with 60 students (again comprising 30 introvert and 30 extrovert learners) experienced a competitive learning method.

\section{B. Instrumentation}

To accomp lish the objectives of this research, two TSEs and a questionnaire were administered. Furthermore, certain materials were used in the teaching procedure throughout both terms which are described in this section.

\section{Test of Spoken English (TSE)}

As noted earlier, the TSE was used for the homogenization process prior to the treatment and another sample of this test was used as the posttest after the course. The TSE is one of the most widely used batteries of assessment of spoken English worldwide which measures the ability of nonnative speakers of Englis h to communicate effectively. This 20minute test comprises five separate sections which are: warm-up questions, response to a picture-prompt, telling a story from a picture, description of a graph, and talking through an amended itinerary. The TSE score consists of a single score of communicative language ability reported on a scale from 20 to 60. Assigned score levels are averaged across items and raters, and the scores are reported in increments of five (i.e. 20, 25, 30, ..., and 60).

\section{Eysenck Personality Inventory (EPI)}

The EPI (Eysenck et al., 1985) is a questionnaire to assess the personality traits of a person. The instrument initially conceptualized personality as two, biologically-based categories of temperament which include: extroversion/introversion and neuroticis $\mathrm{m} / \mathrm{stability.} \mathrm{This} \mathrm{validated} \mathrm{test} \mathrm{consists} \mathrm{of} 57$ Yes/No items. Those who fill out the EPI receive three different kinds of scores: the E score which is related to how much extrovert a person is, the $\mathrm{N}$ score measuring the neuroticism, and the Lie score which tries to measure how socially desirable a person has wanted to prove to be. The $\mathrm{N}$ score is computed out of 24 since it consists of 24 items, the $\mathrm{N}$ score is out of 24 , and the Lie score is out of nine. The Yes/No answers should be given based on the usual way of acting or thinking of an individual. The researchers used the Farsi version provided and validated by Seena Institute of Behavioral Sciences Research in Tehran in order for the respondents to answer the questionnaire more accurately. The answer key and the standard rating scales were also provided in the battery enabling the researchers to use them in the study.

\section{Materials}

The following materials were used in the process of the treatment for all the 120 participants in both groups.

The main textbook used in this research was Interchange 3 by Jack C. Richards. This textbook consists of 16 units which are divided into five levels in the language school. The first intermediate level covers four units of this book and all the other levels following the first intermediate level contain three units each term. The main purpose of this book is to integrate speaking, grammar, vocabulary, pronunciation, listening, reading, and writing. There is a strong focus on both accuracy and fluency. The underlying philosophy of the course holds that language is best learned when it is used for meaningful communication.

Another series used in this study were the Oxford Bookworms Storybooks which are graded at six language stages, fro $m$ the elementary to the advanced level, using the syllabus devised by Tricia Hedge, the founding editor of the series. Vocabulary, syntax, structure, and information load are carefully controlled in this series. Since stage four of Oxford Bookworms is designed for intermediate purposes (the level of the participants in this study), they were used in this treatment. To teach this vocabulary book, the researchers provided the learners with many pictures taken from the Internet and showed them on screen in the classes. Each intermediate level covers 10 units of this book which are preplanned to be related to their course book subjects.

\section{Procedure}




\section{Cooperative Group}

In order to conduct this study, the researchers first administered the TSE among 92 intermediate EFL learners thus choosing 60 learners for the first phase (the cooperative learning procedure) whose scores on the test fell one standard deviation above and below the mean. All the participants were recorded during the test since two raters whose interrater reliability had already been established $(r=0.531$, significant at the 0.01 level 2-tailed) rated these performances.

The next step was to conduct the EPI among the 60 participants thereby dividing them into 30 introverts and 30 extroverts. These 60 learners sat in nine different classes and received the same treatment of cooperative learning during one term which lasted 18 sessions of 90 minutes throughout seven weeks. All nice classes were taught by the same teacher (one of the researchers) using the same method and materials.

The learners were not told about the introversion/extroversion component of the study since the researchers thought it might cause certain complications for learners if they were to know their personality type. To this end, they were just asked to fill out the questionnaire as part of the routine class procedure.

The teacher tried to set up a friendly atmosphere in the classes by making the students introduce themselves to each other the very first session. The students were constantly asked to pay attention to maintaining eye contact while speaking. They were supposed to look at each other instead of the teacher while introducing themselves to one another. It seemed rather hard at first but gradually they got used to it and even started to like it.

Depending on the number of students, they were grouped in clusters of three or four. The grouping was done randomly without paying attention to their introversion or extroversion. Each group member knew that each correct or incorrect answer was of great importance for all the rest of the members of the same group. The students also experienced being in different groups during one term and even one single session in order to learn to work cooperatively with different individuals rather than a specific group. Competitiveness was de-emphasized in each group while group work was encouraged.

Every session, about one page and a half was taught in each class taking an average of four sessions for a unit to be fin ished. Each unit contained a part called snapshot which introduced a new cultural difference to the students. The participants were asked to answer these questions in cooperation.

Every other session, the students were exposed to a new grammar focus. For this part after the instruction was completed, the students were given some extra exercises. These exercises and those of the book were done and checked in groups and as they had to read their answers, they had to first decide in turn-taking (i.e. who was going to read the answer first). There was no force on them on the teacher's side.

Another point was the use of listening transcription which was given to them to be done inside the classroom. The listening part in the Interchange book was designed in a way that it consisted of several speakers so each group was in charge of one of the speakers. The listening was played for them two times. The first time, they were asked not to write anything; rather, they only listened for the general idea. The blanks contained the points which were the main focus of the unit. The interesting point was that they displayed extreme alacrity in doing this activity. The second time, they were asked to listen to the CD and write what they heard after each pause. Once it was done, they checked their answer in each group and started reading out their responses. The listening part also included a chart which had to be filled in after they had done their transcription. The groups were changed for this activity again to enable the learners to experience working with different learners in their class.

The Oxford Word Skills, as discussed earlier, was the vocabulary book used in these classes. Some of the un its were designed in a way that they consisted of two short readings (parts A and B). Each group was responsible for one part of each unit. After they studied those sections, they had to switch their seats and explain each part to the other groups.

The teacher presented the new vocabulary section by jotting down the new words on the board and asking the participants to write a new piece in their groups using the new words accompanied with the grammar focus of the day. If there was enough time, they checked each group's mistakes and would give it to the teacher to double-check their writings.

Every session, the participants were asked to study one chapter of their story book at home and prepare some questions based on that chapter in groups inside the classroom context. These groups were supposed to ask these questions from each other, they were also given sufficient time to decide on the correct answers and then express their ideas. The positive or negative scores went to all the me mbers of each group.

Yet another technique which was used in this group was the use of role play. The participants were helping each other in the process of role play to achieve a shared goal with one another. No one wanted to prove to be the best; rather, they helped each other to have a satisfactory outcome.

Sometimes a penalty was chosen for those groups who failed to accomplish the expected outcome. This was performance of a pantomime by a student who was chosen by the group. This process was so enjoyable for them that they never felt a sense of punishment; indeed, they really liked to keep up with the other students who achieved their goals better.

Immediately after this treatment, the first group of this study which was practicing English in a cooperative way underwent the posttest.

Competitive Group 
The subsequent term, the same participant selection procedure was conducted again with another 80 learners undergoing the TSE, 60 of whom were chosen and subsequently sat for the EPI. There were thus 60 students in nine classes; only this time, the students received a competitive learning modality. Again these students were under study for 18 sessions each lasting 90 minutes. All of these learners were exposed to the same amount of instructions and the same materials again by the same teacher.

The participants were not informed about their psychological traits being studied just as was the case with the previous group. In this condition, the teacher again divided the learners into the groups randomly thus having both introverts and extroverts in each group. These students knew that even if they were in groups, they would be assessed based on their individual efforts and outcomes. To do so, the teacher helped them form various groups differing from one session to the other. Compared to the previous treatment, this setting included less group work.

The teacher's instruction method changed minimally; instead, the way the students practiced every single part changed in comparison with the previous treatment. After the grammar was taught, for instance, the extra exercises and the exercises of the book were done individually. The learners could check their answers with their friends but they could answer only when they were called. The teacher chose the person to answer the questions and not the students themselves.

The questions of the snapshot were answered individually. They did not discus s the issues in specified groups but in an open discussion. One student would start responding to the questions of the snapshot and the other students expressed their own ideas.

This time the Oxford Word Skills was practiced in another way. Half of the class was asked to study part A and the second half was asked to study part B but not in groups. They then sat in pairs and explained the newly-gained information to each other. If the students had to produce a new writing with the new words, they would do it individually and later gave those papers to their teacher to check the writings for them.

They were asked to study one chapter of their story book at home. When it was time for them to make their questions based on each chapter, again the teacher formed their groups but this time whenever they were ready for answering the questions, they did not have time for sharing their ideas; on the other hand, they buzzed to answer the question.

Their questions were made in groups but at the time of answering, they acted individually. They competed against each other on being number one. The one who buzzed sooner would answer sooner and received the positive point only for herself as an individual. They did not have to worry about the wrong answer of one of their group me mbers because the negative point just went to one person. This part was accompanied with a sense of excitement.

In some sessions, the students were asked to summarize the story for themselves and present the summary in the class. They had to be ready because while one of them was summarizing the story, the researchers asked another student to continue the rest of the summary.

The group work was not estimated based on the individual person's answer. During this process, they had to keep their books closed completely and they could not assist each other in the process of answering. The positive and negative points were shown on board to be seen by all the participants. The loser of each group had to play pant omime each session or had to prepare a lecture for the next session of the class.

The same penalty was chosen for the listening transcription part. In this section of the class, there existed no group work. The listening transcription paper was given to all the students to be done individually. All the listening sections were played two times. One time, they only had to listen to the CD without writing anything and another time, they would start writing after every single pause. While they were listening to the $\mathrm{CD}$, they only paid attention to their own listening papers and were asked about it later by their names being called and not voluntarily.

Role play was also used in this group with the teacher's choice of partners. The outcome of that role play was asses sed with praising one of the partners as the best one in regards with the a mount of attaining the course objectives.

This group also underwent the TSE as the posttest of the study at the end of the 18 sessions of competitive learning.

It is worth noting that the learners in both groups practiced speaking in various forms such as narrating a story, role play, and free discussion. The latter was done in a participatory fashion among both groups inviting the students to also choose the topic that they were supposed to talk about.

Four speaking tests were done in this study and each was rated based on the rating scale provided for the test. The rating for both groups was done by two raters (once the inter-rater reliability had been established).

\section{RESULTS}

This section presents the data analysis in a chronological order discussing all the descriptive and inferential statistics conducted. To begin with, the participant selection in both cooperative and competitive groups is described statis tically. Then comes the data analysis of the posttest followed by inferential statistics on the hypotheses. Inter-rater reliability is also discussed.

\section{Partici pant Selection}

\section{Cooperative Group}

As discussed earlier, 92 students took a TSE at the outset from whom 60 were chosen for the two groups of introverts and extroverts undergoing the cooperative treatment. Next, the EPI was administered through which 30 introverts and 30 extroverts were identified within this sample of 60 . To make sure that these 30 intro verts and 30 extroverts bore no 
significant difference in terms of the dependent variable of this study (i.e. oral proficiency) prior to the treatment, the researchers ran an independent samples $t$-test on the mean scores of the two groups on the TSE.

As displayed in Table 1, the means of the scores of the introverts on the TSE was 42.92 while that of the extroverts was 42.83.

TABLE 1

DESCRIPTIVE StA TISTICS OF THE TwO SUBGROUPS IN THE COOPERATIVE GROUP PRIOR TO THE STUDY

\begin{tabular}{|l|l|l|l|l|l|l|}
\hline & $\mathrm{N}$ & Minimum & Maximum & Mean & Std. Deviation & Skewness ratio \\
\hline Introverts & 30 & 40.00 & 50.00 & 42.92 & 2.63296 & 1.39 \\
\hline Extroverts & 30 & 35.00 & 50.00 & 42.83 & 2.60415 & -0.20 \\
\hline Valid N (list wise) & 30 & & & & & \\
\hline
\end{tabular}

As both groups' distribution of scores resembled normality with their skewness ratios falling within the \pm 1.96 range, running a $t$-test was legitimized. As Table 2 below demonstrates, with the $F$ value of 0.016 at the significance level of 0.901 being larger than 0.05 , the variances between the two groups were not significantly different. Therefore, the results of the $t$-test with the assumption of homogeneity of the variances are reported here. As the results indicate $(t=$ $0.123, p=0.902>0.05)$, there was no significant difference between the mean scores of the two groups' oral proficiency prior to the study.

TABLE 2

INDEPENDENT SAMPLES T-TEST OF THE INTROVERTS AND EXTROVERTS IN THE COOPERATIVE GROUP PRIOR TO THE TREATMENT

\begin{tabular}{|c|c|c|c|c|c|c|c|c|c|}
\hline & \multicolumn{2}{|c|}{$\begin{array}{l}\text { Levene's Test for } \\
\text { Equality of Variances }\end{array}$} & \multicolumn{7}{|c|}{$t$-test for Equality of Means } \\
\hline & & & & & & & & $\begin{array}{l}95 \% \mathrm{Co} \\
\text { the Diff }\end{array}$ & Interval of \\
\hline & $F$ & Sig. & $t$ & Df & $\begin{array}{l}\text { Sig. (2- } \\
\text { tailed) }\end{array}$ & $\begin{array}{l}\text { Mean } \\
\text { Difference }\end{array}$ & $\begin{array}{l}\text { Std. Error } \\
\text { Difference }\end{array}$ & Lower & Upper \\
\hline $\begin{array}{l}\text { Equal variances } \\
\text { assumed }\end{array}$ & .016 & .901 & $\begin{array}{l}.12 \\
3\end{array}$ & 58 & .902 & .08333 & .67612 & -1.27 & 1.437 \\
\hline $\begin{array}{l}\text { Equal variances } \\
\text { not assumed }\end{array}$ & & & $\begin{array}{l}.12 \\
3\end{array}$ & 57.9 & .902 & .08333 & .67612 & -1.27 & 1.437 \\
\hline
\end{tabular}

To this end, the researchers could rest assured that any probable difference between the two groups at the end of the study could be attributed to the interaction of the relevant independent variable (i.e. cooperative learning) and the moderator variable (being introvert or extrovert). Having finalized the participants selection process for the cooperative group, the first phase of the treatment was conducted.

\section{Competitive Group}

The second phase of the treatment was for the competitive group. The procedure of participant selection in this phase was very much identical to that of the previous phase: A total of 80 students took the same TSE and 60 of them whose scores fell one standard deviation above and below the mean were selected. These 60 participants subsequently sat for the EPI and, again, 30 introverts and 30 extroverts were identified within this sample of 60 .

To make sure that these 30 introverts and 30 extroverts bore no significant difference in terms of the dependent variable of this study (i.e. oral proficiency) prior to the competitive exercise, the researchers had to compared the means of the two groups. Table 3 below displays the statistics of the scores of the two groups with the introverts' mean on the TSI prior to the treatment being 44 and that of the extroverts 42.5 .

TABLE 3

Descriptive Statistics of the Two SubGroups IN THE COMPETITIVE Group Prior to the Study

\begin{tabular}{|l|l|l|l|l|l|l|}
\hline & $\mathrm{N}$ & Minimum & Maximum & Mean & Std. Deviation & Skewness ratio \\
\hline Introverts & 30 & 40.0 & 50.0 & 44.00 & 3.5598 & .34 \\
\hline Extroverts & 30 & 40.0 & 50.0 & 42.50 & 2.8162 & 2.44 \\
\hline Valid N (listwise) & 30 & & & & & \\
\end{tabular}

As the skewness ratio of the extrovert group exceeded the maximum acceptable degree $(2.44>1.96)$, conducting a parametric test was not legitimized and the researchers had to resort to employing the nonparametric Mann-Whitney test for this procedure. Table 4 shows the results for this statistical procedure $\left(\mathrm{U}=277.5, \mathrm{~N}_{1}=30, \mathrm{~N}_{2}=30, p=0.06>\right.$ 0.05); the two groups' means were not significantly different so any probable differences at the end of the treatment could be attributed to the interaction of the independent variable (i.e. competitive learning) and the moderator variable (being introvert or extrovert)..

TABLE 4

MANN-WHitney TEST: TEST STATISTICS

\begin{tabular}{|l|l|}
\hline \multicolumn{2}{|l|}{ MANN-WHITNEY TEST:TEST STATISTICS } \\
\hline Mann-Whitney U & Score \\
\hline Wilcoxon W & 277.500 \\
\hline Z & 742.500 \\
\hline Asymp. Sig. (2-tailed) & -2.808 \\
\hline
\end{tabular}




\section{Posttest}

Once the treatment in each group was over, the TSE posttest was conducted. Table 5 below displays the descriptive statistics for all four subgroups on the TSE posttest in one table for easier reference prior to presenting the posttest analysis.

TABLE 5

DESCRIPTIVE STATISTICS OFALL FOUR SUBGROUPS ON THE T SE POSTTEST

\begin{tabular}{|l|l|l|l|l|l|l|}
\hline & $\mathrm{N}$ & Minimum & Maximum & Mean & Std. Deviation & Skewness ratio \\
\hline Introverts - Cooperative & 30 & 40.0 & 57.5 & 47.25 & 4.5651 & .28 \\
\hline Extroverts - Cooperative & 30 & 40.0 & 55.0 & 47.25 & 4.6121 & -.27 \\
\hline Introvert s - Compet itive & 30 & 45.0 & 60.0 & 53.00 & 4.2750 & -1.19 \\
\hline Extrovert s - Compet itive & 30 & 40.0 & 55.0 & 45.83 & 4.1695 & .12 \\
\hline Valid N (list wise) & 30 & & & & & \\
\hline
\end{tabular}

\section{Testing the Hypotheses}

To verify all four hypotheses of the study together, a two-way ANOVA was required since there is a dual learning modality (cooperative versus competitive) and also a dual personality style (introversion versus extroversion) involved with one dependent variable (i.e. oral proficiency) at stake. The descriptive statistics of all four subgroups showed norma lity of distribution as is evident from Table 5 above. Furthermore, the Levene's test of equality of error variances showed that the variances among the four subgroups were not significantly different $\left(F_{(3,116)}=0.326, p=0.806>0.05\right)$. Accordingly, running a two-way ANOVA was legitimized. To illustrate the factorial design, the interaction of the two modalities of the independent variable (cooperative versus competitive learning) and moderator variables (extroversion versus introversion) in this study are displayed in Table 6 below.

TABLE 6

BETWEEN-SUBJECTS FACTOR

\begin{tabular}{|l|l|l|l|}
\hline \multicolumn{2}{|c|}{} & Personality type \\
\cline { 3 - 4 } \multicolumn{2}{|c|}{} & Introvert (1) & Extrovert (2) \\
\hline \multirow{2}{*}{ Type of learning } & Cooperative (1) & 30 & 30 \\
\cline { 2 - 4 } & Competitive (2) & 30 & 30 \\
\hline
\end{tabular}

Table 7 below shows the results of the tests of between-subjects effects.

TABLE 7

TESTS OF BETWEEN-SUBJECTS EFFECTS

\begin{tabular}{|l|l|l|l|l|l|}
\hline Source & $\begin{array}{l}\text { Type III Sum of } \\
\text { Squares }\end{array}$ & df & Mean Square & $F$ & Sig. \\
\hline Corrected Model & $911.250^{\mathrm{a}}$ & 3 & 303.750 & 15.622 & .000 \\
\hline Intercept & 280333.333 & 1 & 280333.333 & 14418.031 & .000 \\
\hline Learning Type & 140.833 & 1 & 140.833 & 7.243 & .008 \\
\hline Personality Type & 385.208 & 1 & 385.208 & 19.812 & .000 \\
\hline $\begin{array}{l}\text { Learning Type } * \\
\text { Personality Type }\end{array}$ & 385.208 & 1 & 385.208 & 19.812 & .000 \\
\hline Error & 2255.417 & 116 & 19.443 & & \\
\hline Total & 283500.000 & 120 & & & \\
\hline Corrected Total & 3166.667 & 119 & & & \\
\hline
\end{tabular}

As Table 7 indicates, the significance value was less than $0.05\left(F_{(3,116)}=15.622, p=0.000\right)$. There was a difference between the impact of the two learning modes on all the participants $\left(F_{(1,116)}=7.243, p=0.008<0.05\right)$. Furthermore, there was a significant difference between the introverts and extroverts who participated in this study in general $\left(F_{(1,116)}\right.$ $=19.812, p=0.000<0.05)$.

Finally, as the interaction of the learning type and personality type proved significantly different $\left(F_{(1,116)}=19.812, p\right.$ $=0.000<0.05$ ), the overall conclusion was that the interaction of the two learning types (cooperative and competitive) with the two personality types (extroverts and introverts) proved significant.

As in this univariate two-way ANOVA, there were only two modalities of the independent variable (learning type) and two fixed factors (personality type), running Post-Hoc tests was not feasible since a minimum of three cases are required for such tests. Hence, as the differences proved significant, the researchers had to clarify which group significantly outperformed which through a two-by-two comparison.

The first step was to calculate the descriptive statistics for each of the following groups on the posttest: the 60 introverts in both learning groups, the 60 extroverts in both learning groups, the 60 introverts and extroverts in the cooperative group, and the 60 introverts and extroverts in the competitive group. Table 8 displays the results for the two overall groups of cooperative and competitive learning. 
TABLE 8

DESCRIPTIVE STATISTICS FOR LEARNING TYPE ON THE POSTTEST

\begin{tabular}{|c|c|c|c|c|c|}
\hline \multicolumn{4}{|c|}{ Learning Type } & Statistic & Std. Error \\
\hline \multirow[t]{14}{*}{ Posttest } & \multirow{7}{*}{ 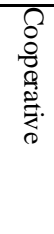 } & Mean & & 47.250 & .5874 \\
\hline & & 95\% Confidence & Lower Bound & 46.075 & \\
\hline & & Interval for Mean & Upper Bound & 48.425 & \\
\hline & & Std. Deviation & & 4.5496 & \\
\hline & & Minimum & & 40.0 & \\
\hline & & Maximum & & 57.5 & \\
\hline & & Skewness & & -.004 & .309 \\
\hline & \multirow{7}{*}{ 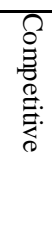 } & Mean & & 49.417 & .7140 \\
\hline & & 95\% Confidence & Lower Bound & 47.988 & \\
\hline & & Interval for Mean & Upper Bound & 50.845 & \\
\hline & & Std. Deviation & & 5.5305 & \\
\hline & & Minimum & & 40.0 & \\
\hline & & Maximum & & 60.0 & \\
\hline & & Skewness & & -.073 & .309 \\
\hline
\end{tabular}

Table 8 shows that the means for the cooperative group was lower than that of the competitive group (47.25 compared to 49.42). Therefore, the competitive group outperformed the cooperative group significantly. Figure 1 displays the above conclusion.

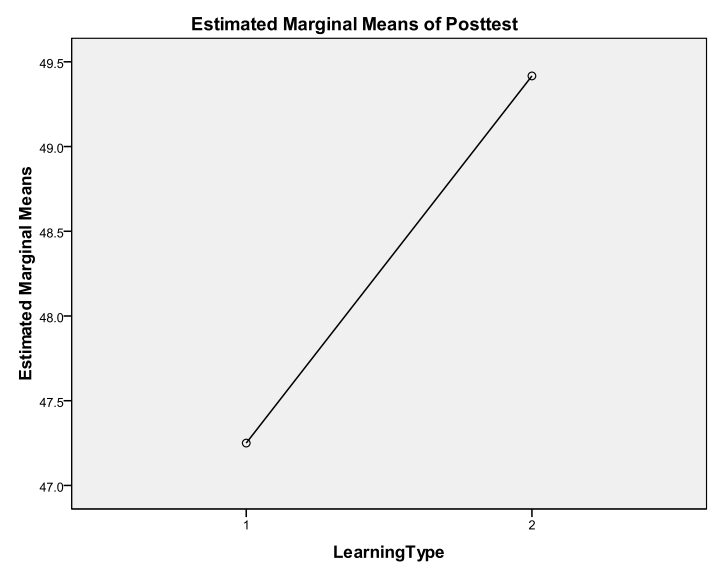

Figure 1 - Descriptive Stat ist ics for Learning Type on the Posttest

Table 9 displays the results for the two overall groups of introverts and extroverts.

TABLE 9

DESCRIPTIVE STATISTICS FOR PERSONALITY TYPE ON THE POSTTEST

\begin{tabular}{|c|c|c|c|c|c|}
\hline \multicolumn{4}{|c|}{ Learning Type } & Statistic & Std. Error \\
\hline \multirow[t]{14}{*}{ Posttest } & \multirow{7}{*}{ 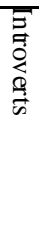 } & Mean & & 50.125 & .6786 \\
\hline & & \multirow{2}{*}{$\begin{array}{l}95 \% \text { Confidence } \\
\text { Interval for Mean }\end{array}$} & Lower Bound & 48.767 & \\
\hline & & & Upper Bound & 51.483 & \\
\hline & & Std. Deviation & & 5.2567 & \\
\hline & & Minimum & & 40.0 & \\
\hline & & Maximum & & 60.0 & \\
\hline & & Skewness & & -.170 & .309 \\
\hline & \multirow{7}{*}{ 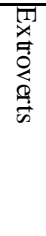 } & Mean & & 46.542 & .5702 \\
\hline & & \multirow{2}{*}{$\begin{array}{l}95 \% \text { Confidence } \\
\text { Interval for Mean }\end{array}$} & Lower Bound & 45.401 & \\
\hline & & & Upper Bound & 47.683 & \\
\hline & & Std. Deviation & & 4.4171 & \\
\hline & & Minimum & & 40.0 & \\
\hline & & Maximum & & 55.0 & \\
\hline & & Skewness & & .001 & .309 \\
\hline
\end{tabular}

Table 9 shows that the means for the extroverts was lower than that of the introverts (46.54 compared to 50.13). Therefore, the introverts outperformed the extroverts significantly. Figure 2 displays the above conclusion. 


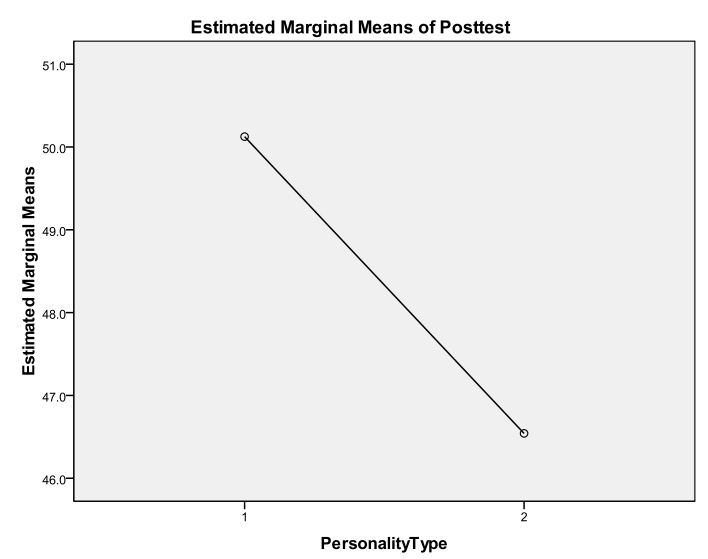

Figure 2 - Descriptive St at istics for Personality Type on the Posttest

Figure 3 below depicts the interaction of the learning modality and the personality type (the dashed line rep resents the competitive setting while the continuous line the cooperative setting). As is evident, while introverts benefited more from the competitive setting compared to the extroverts, there was no difference between the impact of the cooperative setting on introverts and extroverts.

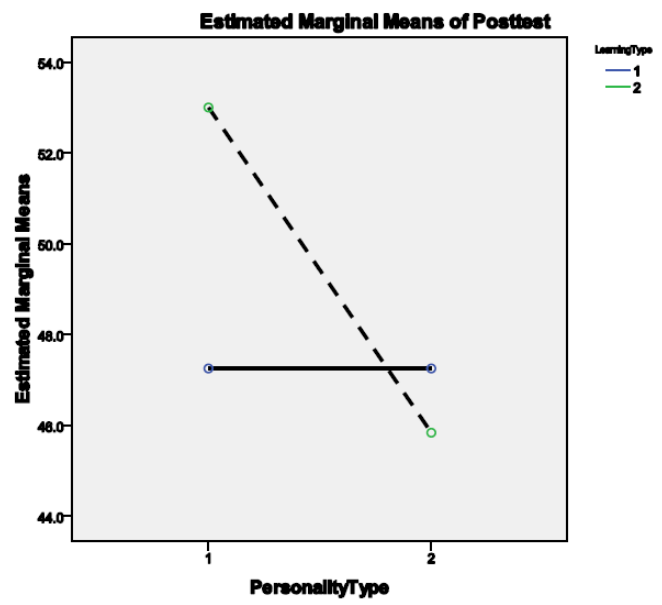

Figure 3 - Interaction of the Learning and Personality Types on the Posttest

Based on the ANOVA table revealing the significant differences, the first hypothes is of the study, that is, there is no significant difference between the effect of competitive and cooperative learning on introvert EFL learners' oral proficiency was rejected as the introverts in the competitive group outperformed the introverts in the cooperative group.

The second hypothes is which read there is no significant difference between the effect of competitive and cooperative learning on extrovert EFL learners' oral proficiency was rejected since the extroverts in the cooperative group outperformed the extroverts in the competitive group.

As for the third hypothesis, competitive learning does not have a significantly different effect on the oral proficiency of introvert and extrovert EFL learners, the introverts outperformed the extroverts in this mode of learning significantly; thus, the third null hypothesis was also rejected.

The fourth and last hypothesis, cooperative learning does not have a significantly different effect on the oral proficiency of introvert and extroverts EFL learners, was not rejected, however, as both subgroups undergoing the cooperative treatment gained the same mean score on the posttest.

Finally, the researchers calculated the parameter estimates of eta squared $\left(\eta^{2}\right)$ to find out how much of the obtained difference could be explained by the two modalities of the independent variable. Table 10 provides that information.

TABLE 10

ESTIMATES OF EFFECT SIZE FOR THE POSTTEST

\begin{tabular}{|l|l|l|l|}
\hline Source & Partial Eta Squared & Noncent.Parameter & Observed Power $^{\text {b }}$ \\
\hline Corrected Model & .288 & 46.867 & 1.000 \\
\hline Intercept & .992 & 14418.031 & 1.000 \\
\hline Learning Type & .059 & 7.243 & .797 \\
\hline Personality Type & .146 & 19.812 & .993 \\
\hline Learning Type * Personality Type & .146 & 19.812 & .993 \\
\hline
\end{tabular}

a. R Squared $=0.288$ (Adjusted R Squared $=0.269$ )

b. Computed using alpha $=0.05$ 
As demonstrated in Table 10, $\eta^{2}$ came out to be 0.06 and 0.15 which indicated that the two settings of learning accounted for $6 \%$ of the variability in the posttest scores while the two personality types did so for $15 \%$ of the variability. Moreover, to determine the strength of the findings of the research, that is, to evaluate the stability of the research findings across samples, effect size was also estimated. The observed power as shown in Table 10, came out to be 0.80 for the learning modality and 0.99 for the personality type which, being above 0.8 , is generally considered a large effect size (Mackey \& Gass, 2005). Therefore, the findings of the study could be considered strong enough for the purpose of generalization.

\section{DISCUSSION}

There were somewhat mixed results in this study. While many studies generally portray the higher effectiveness of cooperative learning (e.g., Deutsch et al., 2006; Johnson et al., 2000; Marashi \& Baygzadeh, 2010; Norman, 2005), this study did not prove categorically that cooperative learning is more advantageous. At first sight, one might think that the results delineated a contrary corollary to the above statement and that competitive learning proves more efficient than cooperative learning as those undergoing the competitive treatment performed better than those in the cooperative setting (with mean scores of 49.42 and 47.25, respectively). Yet th is result is not the categorical finding of this research as although the students in the competitive group were more successful than those in the cooperative group, the extroverts in the cooperative group achieved more than the extroverts in the competitive group. Hence, while competitive teaching was more beneficial to the learners in all, the extrovert group was better off receiving cooperat ive instruction. The reason for this is perhaps due to the very nature of extroverts who seem to be more apt at engaging with one another in group activities.

The above conclusion is further substantiated by the other finding of this research: introverts outperformed extroverts in the competitive group meaning that competitive learning does not match the personality of extroverts. Thus, it is clear accord ing to this study that extroverts do not benefit all that much from competitive learning and seem to do better in environ ments which encourage group activities and synergies.

As for the introverts, a predictable pattern of benefiting from teaching procedures could not be drawn as introverts in both the cooperative and competitive settings benefitted more than extroverts. In other words, introverts were generally better speakers than extroverts. This might be understandable if one puts the somewhat dominant paradigm of extroversion/introversion in context: extroverts outweigh introverts in amount of speech but they do not necess arily gain more than introverts when it comes to oral proficiency as a composite construct with one of its underlying factors being amount of speech. If tested on their own (as was the case in the TSE procedure of this study), they are perhaps not ju xtaposed to a threat from others and may speak individually and freely with less intrinsically -propelled intimidation of the others in the immediate environ ment. Thus, once they feel not jeopardized by others, they function well and perform appropriately and efficiently in terms of oral production.

\section{CONCLUSION}

Based on the findings of this study, it can be concluded that although previous studies mainly supported cooperative learning, the competitive learning modality can also be effective especially when dealing with various kinds of personality traits. The studies carried out earlier had mostly tried to show the effect of these goal structures on the overall achievement of learners and they did not pay much attention to learners' personality type.

The extroverts in this study enjoyed being in both groups but since they were more willing to speak, they enjoyed cooperative learning more as it could be expected. The introverts 'being the reserved type' did not produce speech unless they were asked or prompted to.

Generally speaking, a sizeable fraction of people's focus often goes towards those who express themselves easily. This tendency should, nevertheless, be avoided by teachers in classrooms. While recognizing the essential human right of an individual to have a varying degree of appetite for verbal communication and thus refraining in totality from adopting a reprimanding approach towards the more taciturn individuals, teachers can resort to different techniques in encouraging the somewhat introverted learners in a class to talk. These techniques should not be such that they would give the impression that the teacher has identified the introverts in class and is thence giving them a bonus or an advantage; the last thing the teacher wants under these circumstances is any act on his/her behalf which may lead to a stigmatization of these kind of learners. One must not forget that introverts tend to be rather sensitive as well and approaches which might minimally disrespect them would most probably discourage them hugely from further participation in their community (classroom here being an example of such communities).

Another helpful tip in this regard which is of great value is to avoid putting introverts in groups with a large number of extroverts since the latter do not give the former the chance of speaking. Such groupings would perhaps drive the introverts to feel intimidated by the more outgoing peers in the group and, as a result, be discouraged to participate in class activities and ultimately lose their incentive to learn the language. This is where the role of the teacher as the facilitator gains paramount importance: if the teacher spots such a grouping in class, again the last measure s/he wants to take is to take the more quiet learner from that group and place him/her in another group. Such an act may most probably induce the notion in front of everyone that there is something wrong with that individual which would, in turn, 
shatter him/her before his/her peers. Instead, the teacher could tactfully make a number of changes in some or even all the groups in the class simultaneously, one of them being taking one introvert from an extrovert-packed group to another. Such changes may seem to be part of the normal procedure of the class and provide the introverts the opportunity to engage in less challenging environments.

Indubitably, it is not only teachers who play the major role in the learning process; syllabus designers and textbook writers have a lot to say in this regard too. So me games can be designed for learners to encourage them to learn through both competition and cooperation. This can only be done if teachers and syllabus designers go hand in hand to facilitate the learning process by paying attention to learners' personality types and interests. Teacher guides should also be designed to ease the use of the books.

On a more general and societal level, the settings of classes in many cultures (Iran included) do not still support the full cooperative type. Students are perhaps not ready enough to embrace fully the culture of cooperativeness without competitiveness. Hence, for cooperative learning to demonstrate its potential, ongoing cultural capacity building is required.

The present study aimed at investigating the difference between cooperative and competitive learning among extroverts and introverts when it comes to oral proficiency. The subsequent recommendations are discussed here hoping that they would draw the attention of researchers in continuity of this study.

1. The same study could also be conducted in co-ed contexts to see whether the sitting together of male and female introverts and extroverts in cooperative and competitive setting would bring about different consequential equations.

2. Another de mographic variable which could be adjusted is age. It would be useful to divide the study in various age ranges such as children, teens, or adults. The reaction of introverts and extroverts in various age ranges to the different types of learning contexts would perhaps be variant.

3. The second control variable in this study was language proficiency; another study could be conducted including EFL learners at either ele mentary or advanced levels.

4. A more detailed approach could also be taken in this regard: rather than oral proficiency in general, willingness to speak (WTC) could be taken as the dependent variable of such a study.

5. This study focused on extroversion/introversion as the personality variable of the study; other such researches could be conducted on various different personality factors and cognitive styles to see which learning modes benefits who most.

6. While this study was designed on the theoretical foundation of the confrontation of cooperative and competitive learning, a study could be conducted where the above confrontation would be substituted by the paradigm of complementarity. Accordingly, cooperative and competitive learning modalities would be merged to see how such a package of instruction would impact extroverts and introverts.

\section{REFERENCES}

[1] Brown, H. D. (2000). Principles of language learning and teaching. San Francisco, CA: Addison Wesley Longman.

[2] Burruss, J. D., \& Kaenzig, L. (1999). Introversion: The often forgotten factor impacting the gifted. Virginia Association for the Gifted Newsletter, 21(1), 1-4.

[3] Chamorro-Premuzic, T. (2007). Personality and individual differences. Oxford: Blackwell.

[4] Chuang, Y. Y. (2009). Foreign language speaking assessment: Taiwanese college En glish teachers' scoring performance in the holistic and analy tic rating methods. Asian EFL Journal, 11(1), 150-173.

[5] Deutsch, M., Coleman, P. T., \& Marcus, E. C. (2006). The handbook of conflict resolution: Theory and practice. San Francisco, CA: Jossey-Bass.

[6] Dornyei, Z. (2005). The psychology of the language learner: Individual differences in second language acquisition. Mahwah, NJ: Lawrence Erlbaum Associates.

[7] Ellis, R., \& Yuan, F. (2003). The effects of pre-task planning and on-line planning on fluency, complexity and accuracy in L2 monologic or al production. Applied Linguistics, 24(1), 1-29.

[8] Ey senck, S. B. G., Ey senck, H. J., \& Barrett, P. (1985). A revised version of the psychoticism scale. Journal of Personality and Individual Differences, 6(1), 21-29.

[9] Griffiths, C. (2008). Strategies and good language learners. In C. Griffiths (Ed.), Lessons from good language learners (pp. 8398). Cambridge: Cambridge University Press.

[10] Hedge, T. (2008). Teaching and learning in the lan guage classroom. Oxford: Oxford University Press.

[11] Jianing, X. (2007). Story-telling in the EFL speaking classroom. The Internet TESL Journal, 13(11). Retrieved on April 10, 2010 from www.iteslj.org.

[12] John, O., \& Srivastava, S. (1999). The Big Five traits taxonomy: History, measurement, and theoretical perspectives. In L. Pervin \& O. John (Eds.), Handbook of personality theory and research (pp. 102-153). New York: The Guilford Press.

[13] Johnson, D. W., \& Johnson, R. T. (2008). Social interdependence theory and cooperative learning: The teacher's role. In R. M. Gillies, A. F. Ashman, \& J. Terwel (Eds.), The teacher's role in implementing cooperative learning in the classroom: An introduction (pp. 9-37). New York: Springer.

[14] Johnson, D. W., \& Johnson, R. T. (2009). An educational psychology success story: Social interdependence theory and cooperative learning. An Official Journal of the American Educational Research Association, 38(5), 365-379.

[15] Johnson, D. W., Johnson, R. T., \& Stanne, M. B. (2000). Cooperative learning methods: A meta-analy sis. Minneapolis, MN: University of Minnesota Press. 
[16] Johnson, D. W., Maruyama, G., Johnson, R. T., \& Nelson, D. (1981). Effects of cooperative, competitive, and individualistic goal structures on achievement: A meta-analy sis. Education Resources Information Center, 89(1), 47-62.

[17] Lazaraton, A. (1996). Teaching oral skills. In M. Celce-Murcia (Ed.), Teaching English as a second or foreign language (pp. 103-115). Boston, MA: Heinle \& Heinle.

[18] Lennon, P. (1990). Investigating fluency in EFL: A quantitative approach. Language Learning, 40, 387-412.

[19] Levelt, W. J. M., Roelofs, A., \& Meyer, A. S. (2000). A theory of lexical access in speech production. Behavioral and Brain Sciences, 22, 1-38.

[20] Luchini, L. P. (2007). Integrating the teaching of language as and for communication in the EFL reading class: A case study. Asian EFL Journal, 22(2), 108-121.

[21] Mackey, A., \& Gass, S. (2005). Second lan guage research: Methodology and design. New Jersey: LEA.

[22] Marashi, H., \& Baygzadeh, L. (2010). Using cooperative learning to enhance EFL learners' overall achievement. Iranian Journal of Applied Linguistics, 13(1), 73-98.

[23] Na, L., Lin-Yao, W., \& Ji-Wei, Y. (2008). Relations network in the interactive ESL class: Analysis of individuals, groups, and a whole classroom network. Asian EFL Journal, 10(3), 78-108.

[24] Navidnia, H. (2009). Psychological characteristics of Iranian English language teachers: On the relationship among big five personality traits and teacher efficacy beliefs. Journal of English Language Studies, 1(1), 79-99.

[25] Norman, D. G. (2005). Using STAD in an EFL elementary school classroom in South Korea: Effects on student achievement, motivation, and attitudes toward cooperative learning. Asian EFL Journal, 35(3), 419-454.

[26] Rashtchi, M., \& Key vanfar, A. (2007). ELT: Quick'n'Easy (3rd ed.). Tehran: Rahnama.

[27] Richards, J. C., \& Schmidt, R. W. (2002). Dictionary of lan guage teaching and applied linguistics. New York: Longman.

[28] Riggenbach, H. (1991).Toward an understanding of fluency: A microanalysis of nonnative speaker conversations. Discourse Processes, 14, 423-441.

[29] Sharp, A. (2003). Language learning and awaren ess of personality type in Chinese settings. Asian EFL Journal, 6(2), 1-13.

[30] Shumin, K. (1997). Developing adult EFL students' speaking abilities. English Teaching Forum, 35(3), 8-14.

[31] Senel, M. (2006). Enhancing reading courses in ESL/EFL classes through cooperative learning. Journal of Language and Linguistic Studies, 2(1), 111-125.

[32] Singh, B. (2005). Psychological found ations of education. New Delhi: Mehra.

[33] Spada, N., \& Tomita, Y. (2010). Interactions between type of instruction and type of language feature: A meta-analysis. Language Learning, 60(2), 1-46.

[34] Tarone, E. (2005). Speaking in a second language: Handbook of research in second language teaching and learning. Hillsdale, NJ: Lawrence Erlbaum Associates.

[35] Tuan, T. A., \& Neomy, S. (2007). Investigating group planning in preparation for oral presentations. RELC Journal, 38(1), 104-124.

[36] Walters, L. S. (2000). Social aspects of motivation: Classroom goal structures. Journal of Personality and Social Psychology, 65, 904-915.

[37] Warschauer, M. (1996). Comparing face-to-face and electronic discussion in the second lan guage classroom. CALICO Journal, 13(1), 7-26.

Hamid Marashi is Assistant Professor of Applied Lin guistics, Islamic Azad University at Central Tehran and Executive Manager of the Journal of English Language Studies (JELS). He currently teaches the graduate courses of seminar in TEFL issues, discourse analysis, and teaching language skills and his main areas of research interest include cooperative learning, collaborative teaching, critical thinking, and critical discourse analysis. He has published in international academic journals and also presented in international conferences.

Padideh Dibah holds an MA in TEFL from Islamic Azad University at Central Tehran and has been an English teacher in the private language schools of Tehran for four years. Her main area of research interest is comparing the impact of different ELT methods on learning. 